\title{
Selective Radical Trifluoromethylation of Native Residues in Proteins
}

\author{
Mateusz Imiołek, Gogulan Karunanithy, Wai-Lung Ng, ${ }^{\circledR}$ Andrew J. Baldwin, Véronique Gouverneur, ${ }^{\circ}$ \\ and Benjamin G. Davis*(i) \\ Chemistry Research Laboratory, Department of Chemistry, University of Oxford, Mansfield Road, Oxford OX1 3TA, United \\ Kingdom
}

\section{Supporting Information}

ABSTRACT: The incorporation of fluorine can not only significantly facilitate the study of proteins but also potentially modulate their function. Though some biosynthetic methods allow global residue-replacement, post-translational fluorine incorporation would constitute a fast and efficient alternative. Here, we reveal a mild method for direct protein radical trifluoromethylation at native residues as a strategy for symmetric-multifluorine incorporation on $\mathrm{mg}$ scales with high recoveries. High selectivity toward tryptophan residues enhanced the utility of this direct trifluoromethylation technique allowing ready study of fluorinated protein constructs using ${ }^{19} \mathrm{~F}-\mathrm{NMR}$.

A lthough absent from nearly all-natural products, small organofluorine compounds have found widespread applications from materials, ${ }^{1}$ to clinical diagnostics $\left({ }^{19} \mathrm{~F}-\mathrm{MRI} /{ }^{18} \mathrm{~F}\right.$ $\mathrm{PET})^{2,3}$ and medicinal chemistry (where $30 \%{ }^{4}$ of new small molecule drugs contain $\mathrm{F}$ to alter physicochemical properties ${ }^{5}$ and/or modulate affinity ${ }^{6}$ ). Incorporation of fluorine into biomolecules is more rare but potential applications in structural re-engineering ${ }^{7}$ and as reporter tags for "zero-background" ${ }^{19} \mathrm{~F}$ $\mathrm{NMR}^{8,9}$ raise striking possibilities. For the latter, the benefits include: high sensitivity, extreme responsiveness to local environment, broad chemical shift range and low reactivity once incorporated. ${ }^{10}$ This has helped to elucidate structural, functional and dynamic ${ }^{11,12}$ interactions in receptor function landscapes ${ }^{13}$ and enzymic catalysis. ${ }^{14}$ Indeed, fluorine's features can render it superior over other nuclei in, for example, in-cell NMR spectroscopy ${ }^{15}$ or protein-observed ${ }^{19}$ F-NMR (PrOF) protein-ligand binding. ${ }^{16-19}$

Apart from (semi)synthetic ligations, ${ }^{20}$ two main strategies are used for generating fluorinated proteins: incorporation of fluorinated amino acids using biosynthetic methods or chemical modification. $^{21}$ The former is typically only residue-specific ${ }^{22}$ but can be achieved in a site-selective manner through sense or nonsense codon reassignment (e.g., for positioning of $\mathrm{CF}_{3}$-Lphenylalanine $^{23}$ ). However, for operational simplicity and to avoid identified issues with the former, ${ }^{24}$ the latter modification method has often been preferred as more direct. It has relied largely on reaction of nucleophilic side chains with prosthetic groups bearing fluorine (typically cysteine and lysine) often attached via linkers or prosthetics ${ }^{25,26}$ that can perturb structure and create distance imprecision. ${ }^{24}$ A lack of other methods for installing fluorine into biomolecules has been highlighted as a restriction; ${ }^{24,27}$ due to low relative abundance and roles in interiors, aromatic amino acids are attractive targets. Therefore, direct (hetero)aromatic trifluoromethylation could be a powerful tool allowing (a) "zero/short linker" fluorine incorporation via (b) a higher sensitivity multiequivalent-F system. ${ }^{28,29}$ Here, we describe a novel method that exploits the chemoselectivity of radicals in protein chemistry to achieve this aim (Figure 1).

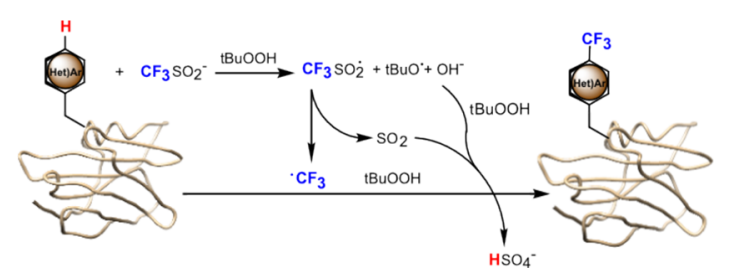

Figure 1. Direct radical trifluoromethylation of protein substrates. $\cdot \mathrm{CF}_{3}$ radical targeting (hetero)aromatic residues can be generated from sodium trifluoromethanesulfinate (NaTFMS, Langlois' reagent) under aqueous, oxidative conditions.

Direct $\mathrm{C}-\mathrm{CF}_{3}$-bond trifluoromethylation presents a striking synthetic challenge in biomolecules. Most strategies for $\mathrm{C}-\mathrm{H}$ functionalization have been applied only to small molecules using methods or conditions essentially incompatible with proteins (elevated temperatures, ${ }^{30}$ organic solvents ${ }^{31}$ or strong acids ${ }^{32}$ ). Among possible strategies, we identified radical-based approaches. ${ }^{33}$ We have demonstrated the benign nature of radicals for $\mathrm{C}-\mathrm{C}$-bond formation through use of a designed unnatural amino acid. ${ }^{34}$ This illustrated radical efficiency under ambient aqueous conditions and operational simplicity. We therefore considered whether a suitable $\cdot \mathrm{CF}_{3}$ precursor might be generated that could allow natural amino acid modification.

Various putative $\cdot \mathrm{CF}_{3}$ sources ${ }^{35}$ were tested using model amino acid substrates. Langlois' reagent (NaTFMS) proved most promising via multiple redox initiation modes (e.g., transitionmetal-free, photocatalytic) under mild conditions. ${ }^{36-38}$ Baran et al. identified that NaTFMS may be used to modify small molecule $N$-heterocycle caffeine when spiked into cell lysate, which has "important implications in the area of bioconjugation". ${ }^{39}$ Advantageously, ${ }^{19} \mathrm{~F}-\mathrm{NMR}$ allowed us ready reactivity screening of all abundant natural amino acids (SI Figure S1) and revealed selective reactivity of $\mathrm{NaTFMS} / \mathrm{TBHP}^{39}$ with only aromatic amino acids and free cysteine ((hetero)arene- $\mathrm{C}-\mathrm{H}$ or $\mathrm{Cys}-\mathrm{S}-\mathrm{H}$ trifluoromethylation) and none toward any other natural amino acids. ${ }^{19} \mathrm{~F}$-NMR suggested near homogeneous product formation from tryptophan (Trp) and cysteine (Cys); low levels of products

Received: September 25, 2017

Published: January 5, 2018 
from His, Tyr and Phe, appeared as complex mixtures of apparent regioisomers.

Next, limited $(<40 \%)$ conversion competition assays (Figure 2) using mixtures of equimolar Trp, Phe, Tyr, Cys, His, Met with

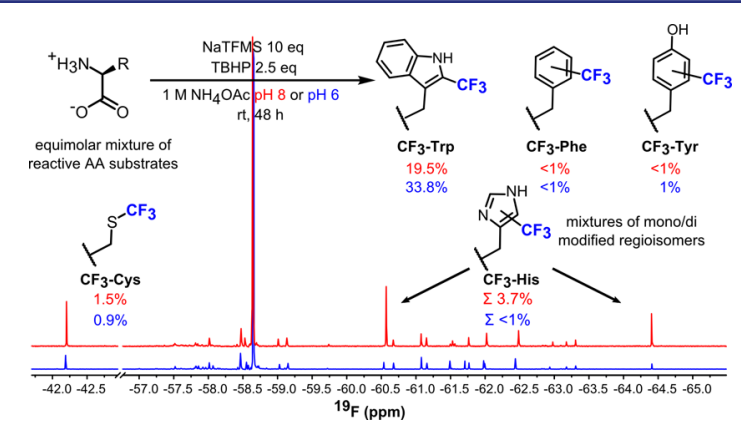

Figure 2. Limited-conversion competition assay of natural amino acids $(0.03 \mathrm{mmol})$ revealed chemo- and regio-selectivity toward Trp with minor products (Cys and lower levels of Phe, His, Tyr isomers, determined by ${ }^{19}$ F-NMR, LC-MS). See Figure S3 for parallel reaction in absence of Cys.

NaTFMS/TBHP were used to assess residue-specific selectivity. These revealed preferential formation of the Trp-C2 isomer at a $k_{\text {rel }}>\sim 7.5$-fold. This could be further increased to $k_{\text {rel }}>\sim 30$-fold by lowering the $\mathrm{pH}$ to 6 (SI Table T2), potentially due to reduced reactivity of protonated His residues. The main side reaction was oxidative dimerization of Cys without trifluoromethylation. These observations suggested not only the cysteine disulfide is inert but in the absence of free Cys, strongly chemo- and regioTrp-selective trifluoromethylation might be possible in proteins. This was confirmed by a similar competition reaction in the absence of Cys (SI Figure S3), along with His modification as minor $(<1: 24)$ side-reaction. Optimization of the reaction toward Trp revealed the key role of $\mathrm{pH}$ (SI Table T3). In weakly or nonbuffered aqueous conditions, rapid acidification was observed, consistent with a mechanism that leads to hydrogensulfate formation (Figure 1). ${ }^{40}$ Useful conversions to $\mathrm{CF}_{3}-\mathrm{Trp}$ (>50\%) were obtained at a moderate $\mathrm{pH} \sim 6$ (Figure S4), optimal for most biomolecules.

Together, these results prompted investigation in more complex peptidic and protein substrates. First, reaction of $\mathrm{N}$ acetyl-L-tryptophanamide confirmed reactivity and identical regio-selectivity to that seen for Trp. Second, as a simple model peptide, we chose melittin, a 26-residue peptide with a single Trp residue at Trp19. Use of excess NaTFMS/TBHP with methionine as an oxidative buffer allowed short reaction times (Figure 3). The exclusive site of modification at $\operatorname{Trp} 19$ was confirmed by LC-MS/MS analysis (SI Figure S3); Trp19 oxidation and dual Trp19 $\mathrm{CF}_{3}$-ylation were observed under prolonged conditions. 4-Hydroxy-TEMPO not only allowed ready termination of the reaction at varied time points but also confirmed the radical-mediated nature.

As a natural protein substrate, we chose model hemoproteinhorse heart myoglobin $(\mathrm{Mb})$. Mb contains two buried Trp (Trp7, Trp14) in the presence of several other potentially reactive, more accessible residues (SI Figure S6). Optimization of conditions ( $\mathrm{pH}$, temperature, reactants loading, SI Table T4, SI Figure S7) allowed modulation of reactivity by $\mathrm{CF}_{3}$ copy-number. In this way, at $\mathrm{pH} 6(100 \mathrm{mM}$ ammonium acetate $), 0^{\circ} \mathrm{C}$, using 200 equiv NaTFMS after $10 \mathrm{~min}$ we were able to create myoglobin bearing primarily one or two $\mathrm{CF}_{3}$ groups (Figure 4a). Higher equivalents of Langlois' reagent allowed further shortening of reaction times,

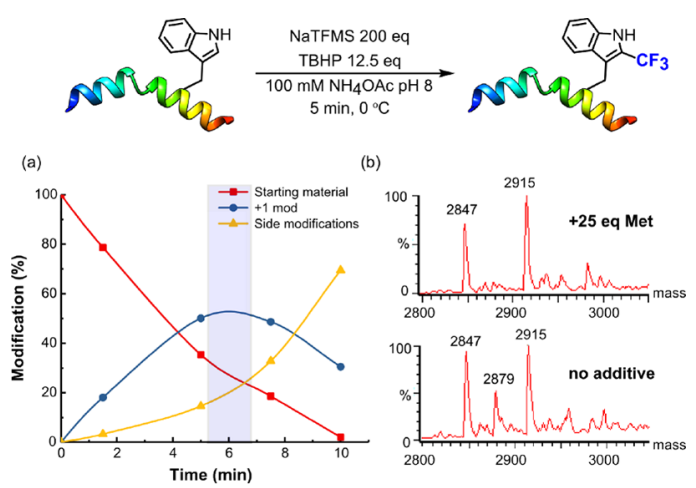

Figure 3. Reaction of melittin $\left(\mathrm{MW}_{\text {calc }}=2847\right)$ with NaTFMS/TBHP. (a) Relative conversions from LC-MS with the optimal reaction time highlighted in blue. (b) Deconvoluted LC-MS spectra of reaction mixtures after $5 \mathrm{~min} \pm$ Met. Undesired oxidation $(+32)$ is curtailed by sacrificial reductant giving melittin- $\operatorname{TrpCF}_{3}\left(+68, \mathrm{MW}_{\text {calc }}=2915\right.$, $\mathrm{MW}_{\text {found }}=2915$ ).

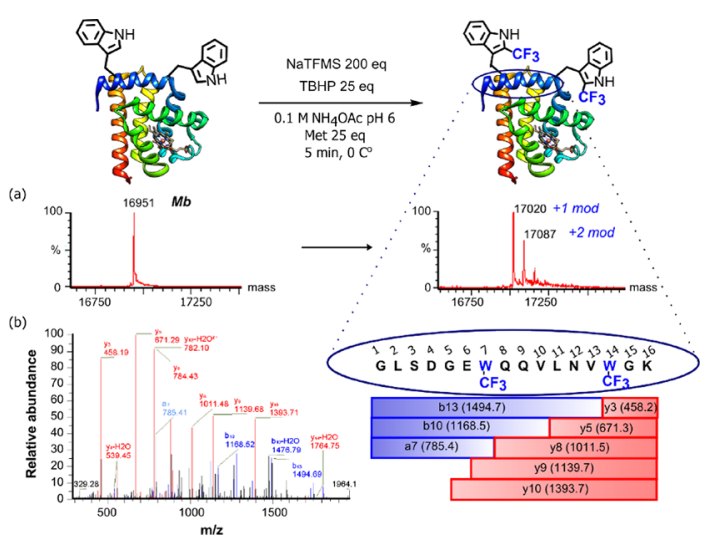

Figure 4. Direct trifluoromethylation of proteins (a) myoglobin $(\mathrm{Mb}$, $\left.\mathrm{MW}_{\text {calc }}=16951.5\right)$ deconvoluted LC-MS spectrum showing singly$\left(\mathrm{MW}_{\text {calc }}=17019, \mathrm{MW}_{\text {found }}=17020\right)$ and doubly- modified $\left(\mathrm{MW}_{\text {calc }}=\right.$ $\left.17087, \mathrm{MW}_{\text {found }}=17087\right)$, (b) tryptic-LC-MS/MS confirmed siteselectivity at Trp7 and Trp14.

without apparent adverse effects on protein (SI Table T4, entries $5,6)$. In contrast to literature observations, ${ }^{39}$ we observed no significant influence of $\mathrm{Zn}^{2+}$ as an additive. Control of $\mathrm{pH}$ also minimized concomitant oxidation (SI Figure S8). Tryptic digestLCMS/MS revealed that Trp7 and Trp14 were the dominant sites of modification (Figure $3 b$ and SI Figure S9) despite their buried nature, highlighting the low steric hindrance of $\cdot \mathrm{CF}_{3}$, even in these congested environments. This accessibility to buried sites complements existing nucleophilic, prosthetic-mediated methods, which are more applicable to exposed sites, requiring partial denaturation to access buried sites. ${ }^{41-43}$ Similarly, accessibility is needed for standard labeling of Cys with fluorinated tags. Importantly, CD spectroscopy revealed that trifluoromethylation had negligible influence on the structure of $\mathrm{Mb}-\mathrm{TrpCF}$ protein (SI Figure S10).

Next, we tested the prospective utility of our developed direct trifluoromethylation as a tool for enabling protein ${ }^{19} \mathrm{~F}-\mathrm{NMR}$. Pleasingly, mg-scale reactions allowed straightforward "labeling" of $\mathrm{Mb}$ with $\mathrm{CF}_{3}$ with $\sim 65-80 \%$ recovery. As a proof-of-principle, we used ${ }^{19} \mathrm{~F}-\mathrm{NMR}$ to directly probe sites of modification (Figure $5 a)$. The native protein spectra of modified $\mathrm{Mb}$ revealed two major ${ }^{19} \mathrm{~F}$-peaks. To elucidate their origin, protein was digested with trypsin (to free residues from their microenvironment and 


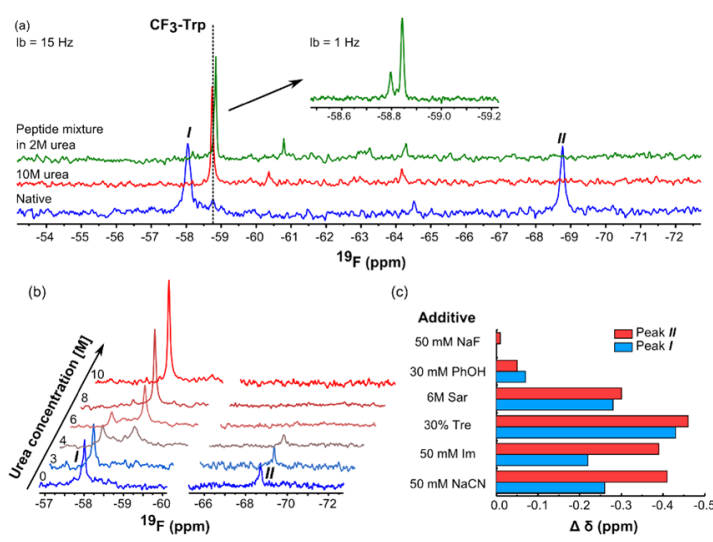

Figure 5. ${ }^{19} \mathrm{~F}-\mathrm{NMR}$ analyses enabled by direct trifluoromethylation. (a) ${ }^{19} \mathrm{~F}-\mathrm{NMR}$ of $\mathrm{CF}_{3} \mathrm{Trp}-\mathrm{Mb}\left(700 \mu \mathrm{M}\right.$ in $100 \mathrm{mM} \mathrm{NH}_{4} \mathrm{OAc}, \mathrm{pH} 8$, blue), denatured by $10 \mathrm{M}$ urea $(300 \mu \mathrm{M}$, red $)$ and peptide mixture from tryptic digest (from $2 \mathrm{mM}$ protein, green). Dashes indicate chemical shift for small molecule model. Inset at higher field with individual Trp resolved. (b) Urea titration by ${ }^{19} \mathrm{~F}-\mathrm{NMR}$ (protein $200-400 \mu \mathrm{M}$ ). (c) Chemical shift differences from ligands in PrOF, protein concentration (100-300 $\mu \mathrm{M})$.

remove nonequivalence); the resonances collapsed to $\delta_{\mathrm{F}}-58.8$ $\mathrm{ppm}$, in good agreement to that for 2- $\mathrm{CF}_{3}-\mathrm{Trp}$ in model Trp- $\mathrm{CF}_{3}$ bis-amide $\left(\delta_{\mathrm{F}}-58.76\right)$. This was further reinforced by denaturative ${ }^{19}$ F-NMR structural analyses: ${ }^{44}$ titration with urea induced a gradual change in chemical shift (Figure $5 b$ ) that could be explained by a known progressive loss of secondary structure in $\mathrm{Mb}$ under such conditions. ${ }^{45}$ Treatment with $10 \mathrm{M}$ urea resulted in full coalescence to $\delta$-58.74 ppm (Figure 5a, full spectrum Figure S11). ${ }^{46,47}$

We extended essentially the same protocol to other model proteins with different folds and Trp copy number: pantothenate synthetase (PanC with single Trp306) and more demanding enzyme lysozyme (Ly), which possesses six potentially reactive Trp (Trp28, Trp62, Trp63, Trp108, Trp111 and Trp123) and eight Cys engaged within each other as disulfides. Both trypticLC-MS/MS and ${ }^{19}$ F-NMR (SI Figures S12-17) not only confirmed Trp residues as primary modification sites in both proteins but also revealed no reaction of Cys residues, consistent with our prior observations. Thermal denaturation also gave rise to resonance coalesence, as for $\mathrm{Mb}$ (SI Figure S19). We were also able to determine that trifluoromethylation had negligible influence upon both the structure of Ly (via CD, SI Figure S20) but also upon its enzymatic function (SI Figure 22, SI Table T5), which was essentially unaltered. We were also able to use this fully active $\mathrm{CF}_{3}$-ylated Ly in quantitative ${ }^{19} \mathrm{~F}-\mathrm{NMR} \mathrm{PrOF}^{16-19}$ (SI Figure 21) to directly determine the binding of known alkaloid inhibitor ligand berberine $\left(K_{\mathrm{d}} 20 \mu \mathrm{M}\right.$, consistent with values determined by complementary methods ${ }^{48}$ ). The potential of our direct trifluoromethylation method was also demonstrated in more complex structural experiments for different proteinligand states studied by PrOF. ${ }^{16-19}$ This allowed observation of displacement of water bound at hemin iron (which we confirmed by $\mathrm{UV}$-vis ${ }^{49}$ was retained after $\mathrm{CF}_{3}$-ylation, Figure S23) by known ligands cyanide, fluoride, imidazole $(\mathrm{Im})^{50}$ (Figure 5c, full spectra Figure S24). ${ }^{16}$ We also tested effects of common osmo/ cryo- protectants (sarcosine - Sar, trehalose - Tre $)^{51}$ and putative ligand phenol. ${ }^{52} \mathrm{CN}^{-}$, Im caused clear upfield shifts, consistent with being known specific ligands. ${ }^{47}$ Both Trp residues are located within the same helix; both signals reported changes, yet these were more pronounced for more-tightly packed Trp14
(Figure S26). Interestingly, known ligand $\mathrm{F}^{-}$did not trigger a change in chemical shift suggesting that this small ligand has a negligible impact on overall protein conformation. Conversely, Tre and Sar caused globally observed changes, consistent with nonspecific interactions or changes in solute properties, in agreement with the mode of actions of these compounds. ${ }^{53}$ Phenol, which inhibits the dehaloperoxidase activity of myoglobins, ${ }^{52}$ showed only small changes implying only nonspecific binding, likely not at hemin (Figure S25).

In conclusion, we have demonstrated direct trifluoromethylation of natural residues in proteins. Tuned radical chemistry allows fast $(<10 \mathrm{~min})$ and chemo-selective modification of Trp with a useful but not absolute selectivity over other putative residues in peptidic systems and proteins. This method appears to provide a selective and direct protocol for trifluoromethylation of proteins. Methods exploiting photochemical generation ${ }^{54,55}$ or the use of electrophilic alkylation chemistry ${ }^{56}$ suggest lower and/ or differing selectivities. Interestingly, in the context of the known ambiguity of $\cdot \mathrm{CF}_{3}$ toward heteroarenes, ${ }^{57}$ this selectivity seems to exploit electrophilic polarity; our preliminary results using known precursors to nucleophilic $\cdot \mathrm{CF}_{2} \mathrm{Me}$ under essentially identical conditions failed. Trp vs His selectivity is increased at $\mathrm{pH} 6$ (Table $\mathrm{T} 2$ ), also consistent with lower reactivity of electrophilic $\cdot \mathrm{CF}_{3}$ toward protonated His. It allows direct access to ${ }^{19} \mathrm{~F}-\mathrm{NMR}$ experiments without the requirement of additional mutation of protein substrates and use of linkers, as is currently the case. ${ }^{58}$ In particular, we showed through fractional $\mathrm{CF}_{3}$ “"labeling" ${ }^{19} \mathrm{~F}$ NMR spectra can be obtained directly with no significant line broadening. ${ }^{59}$ Although Trp residues are rare, their frequent role and in proximity to protein-ligand/protein interactions and presence at hydrophobic interfaces makes them useful probes in PrOF assays. ${ }^{60-63}$ We speculate too that the reactivity observed here with typically inaccessible sites reflects both the lack of bulk (no 'linker'/ "zero size") and prior observations that biphasic/ interfacial regions enhance small molecule radical reactions. ${ }^{40}$ It therefore complements other Trp-modification, such as the use of $\mathrm{Rh}$-carbenoids that work best with surface residues and currently allow more generality in modifying group than the method we present here. ${ }^{42}$ Other applications can also be envisaged: tuning of intrinsic Trp fluorescence ${ }^{64}$ or physicochemical effects via fluorination (e.g., "Teflon" proteins ${ }^{65}$ ). We observed even low levels of fluorine incorporation altered fluorescence spectra (SI Figure S27) and changed chromatographic behaviors (SI Figure S28).

\section{ASSOCIATED CONTENT}

\section{S Supporting Information}

The Supporting Information is available free of charge on the ACS Publications website at DOI: 10.1021/jacs.7b10230.

Experimental and characterization data (PDF)

\section{AUTHOR INFORMATION}

Corresponding Author

*Ben.Davis@chem.ox.ac.uk

ORCID

Wai-Lung Ng: 0000-0003-2892-6318

Véronique Gouverneur: 0000-0001-8638-5308

Benjamin G. Davis: 0000-0002-5056-407X

Notes

The authors declare no competing financial interest. 


\section{ACKNOWLEDGMENTS}

Funded under the EU Horizon 2020 programme, Marie Skłodowska-Curie grant agreement No. 675071, and by a Croucher Foundation Fellowship.

\section{REFERENCES}

(1) Leclerc, N.; Chavez, P.; Ibraikulov, O. A.; Heiser, T.; Leveque, P. Polymers 2016, 8, 11.

(2) Tirotta, I.; Dichiarante, V.; Pigliacelli, C.; Cavallo, G.; Terraneo, G.; Bombelli, F.; Metrangolo, P.; Resnati, G. Chem. Rev. 2015, 115, 1106.

(3) Preshlock, S.; Tredwell, M.; Gouverneur, V. Chem. Rev. 2016, 116, 719.

(4) Zhou, Y.; Wang, J.; Gu, Z.; Wang, S.; Zhu, W.; Acena, J. L.; Soloshonok, V. A.; Izawa, K.; Liu, H. Chem. Rev. 2016, 116, 422.

(5) Purser, S.; Moore, P. R.; Swallow, S.; Gouverneur, V. Chem. Soc. Rev. 2008, 37, 320.

(6) Muller, K.; Faeh, C.; Diederich, F. Science 2007, 317, 1881.

(7) Marsh, E. N. Acc. Chem. Res. 2014, 47, 2878.

(8) Danielson, M. A.; Falke, J.J. Annu. Rev. Biophys. Biomol. Struct. 1996, 25, 163.

(9) Wang, G.; Zhang, Z. T.; Jiang, B.; Zhang, X.; Li, C.; Liu, M. Anal. Bioanal. Chem. 2014, 406, 2279.

(10) Yu, J. X.; Hallac, R. R.; Chiguru, S.; Mason, R. P. Prog. Nucl. Magn. Reson. Spectrosc. 2013, 70, 25.

(11) Leung, R. L. C.; Robinson, M. D. M.; Ajabali, A. A.; Karunanithy, G.; Lyons, B.; Raj, R.; Raoufmoghaddam, S.; Mohammed, S.; Claridge, T. D. W.; Baldwin, A. J.; Davis, B. G. J. Am. Chem. Soc. 2017, 139, 5277.

(12) Manglik, A.; Kim, T. H.; Masureel, M.; Altenbach, C.; Yang, Z. Y.; Hilger, D.; Lerch, M. T.; Kobilka, T. S.; Thian, F. S.; Hubbell, W. L.; Prosser, R. S.; Kobilka, B. K. Cell 2015, 162, 1431.

(13) Ye, L.; Van Eps, N.; Zimmer, M.; Ernst, O. P.; Prosser, R. S. Nature 2016, 533, 265.

(14) Kim, T. H.; Mehrabi, P.; Ren, Z.; Sljoka, A.; Ing, C.; Bezginov, A.; Ye, L.; Pomes, R.; Prosser, R. S.; Pai, E. F. Science 2017, 355, eaag2355.

(15) Ye, Y.; Liu, X.; Chen, Y.; Xu, G.; Wu, Q.; Zhang, Z.; Yao, C.; Liu, M.; Li, C. Chem. - Eur. J. 2015, 21, 8686.

(16) Gee, C. T.; Arntson, K. E.; Urick, A. K.; Mishra, N. K.; Hawk, L. M.; Wisniewski, A. J.; Pomerantz, W. C. Nat. Protoc. 2016, 11, 1414.

(17) Urick, A. K.; Calle, L. P.; Espinosa, J. F.; Hu, H.; Pomerantz, W. C. ACS Chem. Biol. 2016, 11, 3154.

(18) Arntson, K. E.; Pomerantz, W. C. J. Med. Chem. 2016, 59, 5158.

(19) Urick, A. K.; Hawk, L. M.; Cassel, M. K.; Mishra, N. K.; Liu, S.; Adhikari, N.; Zhang, W.; dos Santos, C. O.; Hall, J. L.; Pomerantz, W. C. ACS Chem. Biol. 2015, 10, 2246.

(20) Malins, L. R.; Payne, R. J. Curr. Opin. Chem. Biol. 2014, 22, 70.

(21) Frieden, C.; Hoeltzli, S.; Bann, J. Methods Enzymol. 2004, 380, 400.

(22) Marsh, E. N.; Suzuki, Y. ACS Chem. Biol. 2014, 9, 1242.

(23) Hammill, J. T.; Miyake-Stoner, S.; Hazen, J. L.; Jackson, J. C.; Mehl, R. A. Nat. Protoc. 2007, 2, 2601.

(24) Kitevski-LeBlanc, J. L.; Prosser, R. S. Prog. Nucl. Magn. Reson. Spectrosc. 2012, 62, 1.

(25) Gerig, J. T. Prog. Nucl. Magn. Reson. Spectrosc. 1994, 26, 293.

(26) Basle, E.; Joubert, N.; Pucheault, M. Chem. Biol. 2010, 17, 213.

(27) Tian, H.; Furstenberg, A.; Huber, T. Chem. Rev. 2017, 117, 186.

(28) Rapidly rotating $\mathrm{CF}_{3}$ produces strong, narrow NMR signal.

(29) Kim, H. J.; Howell, S. C.; Van Horn, W. D.; Jeon, Y. H.; Sanders, C. R. Prog. Nucl. Magn. Reson. Spectrosc. 2009, 55, 335.

(30) Natte, K.; Jagadeesh, R. V.; He, L.; Rabeah, J.; Chen, J.; Taeschler, C.; Ellinger, S.; Zaragoza, F.; Neumann, H.; Brückner, A.; Beller, M. Angew. Chem., Int. Ed. 2016, 55, 2782.

(31) Nagib, D. A.; MacMillan, D. W. Nature 2011, 480, 224.

(32) Lin, J.; Li, Z.; Kan, J.; Huang, S.; Su, W.; Li, Y. Nat. Commun. 2017, 8,14353 .

(33) Yan, M.; Lo, J. C.; Edwards, J. T.; Baran, P. S. J. Am. Chem. Soc. 2016, 138, 12692.

(34) Schaller, M. F.; Fung, M. K.; Wright, T. H.; Katz, M. E.; Kent, D. V. Science 2016, 354, 225.

(35) Jiang, Y.; Yu, H.; Fu, Y.; Liu, L. Sci. China: Chem. 2015, 58, 673.
(36) Lefebvre, Q. Synlett 2016, 28, 19.

(37) Li, L.; Mu, X.; Liu, W.; Wang, Y.; Mi, Z.; Li, C. J. J. Am. Chem. Soc. 2016, 138, 5809.

(38) Wang, D.; Deng, G.; Chen, S.; Gong, H. Green Chem. 2016, 18, 5967.

(39) Fujiwara, Y.; Dixon, J. A.; O’Hara, F.; Funder, E. D.; Dixon, D. D.; Rodriguez, R. A.; Baxter, R. D.; Herle, B.; Sach, N.; Collins, M. R.; Ishihara, Y.; Baran, P. S. Nature 2012, 492, 95.

(40) Ji, Y.; Brueckl, T.; Baxter, R.; Fujiwara, Y.; Seiple, I.; Su, S.; Blackmond, D.; Baran, P. S. Proc. Natl.Acad. Sci.U.S. A. 2011, 108, 14411.

(41) Seim, K. L.; Obermeyer, A. C.; Francis, M. B. J. Am. Chem. Soc. 2011, 133, 16970.

(42) Antos, J. M.; McFarland, J. M.; Iavarone, A. T.; Francis, M. B. J. Am. Chem. Soc. 2009, 131, 6301.

(43) Seki, Y.; Ishiyama, T.; Sasaki, D.; Abe, J.; Sohma, Y.; Oisaki, K.; Kanai, M. J. Am. Chem. Soc. 2016, 138, 10798.

(44) Lian, C.; Le, H.; Montez, B.; Patterson, J.; Harrell, S.; Laws, D.; Matsumura, I.; Pearson, J.; Oldfield, E. Biochemistry 1994, 33, 5238.

(45) Muthuselvi, L.; Miller, R.; Dhathathreyan, A. Chem. Phys. Lett. 2008, $465,126$.

(46) We tentatively assign I as Trp7 and II as Trp 14 by comparison with universally labelled [4F]-Trp-Mb despite highly dispersed peaks in those studies. See the following ref:

(47) Pearson, J. G.; Montez, B.; Le, H. B.; Oldfield, E.; Chien, E. Y. T.; Sligar, S. G. Biochemistry 1997, 36, 3590.

(48) Jash, C.; Kumar, G. S. RSC Adv. 2014, 4, 12514

(49) Richards, M. P. Antioxid. Redox Signaling 2013, 18, 2342.

(50) Winkler, W. C.; Gonzalez, G.; Wittenberg, J. B.; Hille, R.; Dakappagari, N.; Jacob, A.; Gonzalez, L. A.; Gilles-Gonzalez, M. A. Chem. Biol. 1996, 3, 841 .

(51) Olsson, C.; Jansson, H.; Swenson, J. J. Phys. Chem. B 2016, 120, 4723.

(52) Huang, X.; Wang, C. X.; Celeste, L. R.; Lovelace, L. L.; Sun, S. F.; Dawson, J. H.; Lebioda, L. Acta Crystallogr., Sect. F: Struct. Biol. Cryst. Commun. 2012, 68, 1465.

(53) Rahman, S.; Ali, S. A.; Islam, A.; Hassan, M. I.; Ahmad, F. Arch. Biochem. Biophys. 2016, 591, 7.

(54) Labroo, V. M.; Labroo, R. B.; Cohen, L. A. Tetrahedron Lett. 1990 , 31,5705 .

(55) Cheng, M.; Zhang, B.; Cui, W.; Gross, M. L. Angew. Chem., Int. Ed. 2017, 56, 14007.

(56) Capone, S.; Kieltsch, I.; Flögel, O.; Lelais, G.; Togni, A.; Seebach, D. Helv. Chim. Acta 2008, 91, 2035.

(57) O'Hara, F.; Blackmond, D. G.; Baran, P. S. J. Am. Chem. Soc. 2013, $135,12122$.

(58) Abboud, M. I.; Hinchliffe, P.; Brem, J.; Macsics, R.; Pfeffer, I.; Makena, A.; Umland, K. D.; Rydzik, A. M.; Li, G. B.; Spencer, J.; Claridge, T. D.; Schofield, C. J. Angew. Chem., Int. Ed. 2017, 56, 3862.

(59) Kitevski-LeBlanc, J. L.; Evanics, F.; Prosser, R. S. J. Biomol. NMR 2010, 48, 113

(60) Chilkoti, A.; Tan, P. H.; Stayton, P. S. Proc. Natl. Acad. Sci. U. S. A. $1995,92,1754$.

(61) Englert, M.; Nakamura, A.; Wang, Y. S.; Eiler, D.; Söll, D.; Guo, L. T. Nucleic Acids Res. 2015, 43, 11061.

(62) Ma, H.; Yang, X.; Lu, Z.; Liu, N.; Chen, Y. PLoS One 2014, 9, e103792.

(63) Nakamura, A.; Tsukada, T.; Auer, S.; Furuta, T.; Wada, M.; Koivula, A.; Igarashi, K.; Samejima, M. J. Biol. Chem. 2013, 288, 13503.

(64) Lakowicz, J. R. Principles of fluorescence spectroscopy; 3rd ed.; Springer: New York, NY, 2006

(65) Budisa, N.; Pipitone, O.; Siwanowicz, I.; Rubini, M.; Pal, P. P.; Holak, T. A.; Gelmi, M. L. Chem. Biodiversity 2004, 1, 1465. 